\title{
Physico-mechanical properties of coir and jute fibre reinforced hybrid polyethylene composites
}

\author{
Shakil Ahmed, Ashraful Ahsan and *Mahbub Hasan \\ Department of Materials and Metallurgical Engineering, \\ Bangladesh University of Engineering and Technology, Dhaka 1000, Bangladesh \\ *E-mail: mahbubmmebuet@gmail.com, \\ Phone: +8801820291811; Fax: +88029665618
}

\begin{abstract}
Composite materials are materials made from two or more constituent materials with significantly different physical or chemical properties, that when combined will produce a material with characteristics difference from the individual components. Hybrid composite means a special type of composite which contains more than one fibre material as a reinforcing filler. Multiple fibres reinforced composite gives a wide variety of mechanical properties with respect to single fibre containing composite. The eco-friendly nature, as well as processing advantage, light-weight and low cost, have enhanced attraction and interest of natural fibre reinforced composites. The objective of the present research is to study the mechanical properties of jute-coir fibre reinforced hybrid polyethylene composites. Composites were manufactured by using a hot press machine at three levels of fibre loading (5 wt.\%, $10 \mathrm{wt} . \%$, and $15 \mathrm{wt}$. \%). Tensile, flexural, impact, and hardness tests were conducted for mechanical characterisation. Water absorption and scanning electron microscopic analysis were carried out as part of physical evaluation. Tensile test of composite showed a decreased tensile strength trend and increased Young's modulus trend with the increase in fibre content. During flexural, impact, and hardness tests, the flexural strength, flexural modulus, impact strength, and hardness were increased with increase in fibre loading. Water absorption also increased with increase in fibre loading. Scanning electron microscopic analysis showed the strongest adhesion between fibre and matrix in the $15 \%$ fibre reinforced composite. Based on the fibre loading used in this study, $15 \%$ fibre reinforced composite resulted in the best set of mechanical properties.
\end{abstract}

Keywords: Mechanical properties; SEM; jute; coir; polyethylene; hybrid composite.

\section{INTRODUCTION}

Nowadays, hybrid composite is a popular name because of its capability of providing various properties that cannot be attained in binary systems that contain only one type of fibre dispersed in a matrix. Both synthetic and natural fibres can be used as a filler material. Replacement of conventional synthetic fibres with natural fibres for reinforcement in polymer matrix composites can lead to a green, renewable path of applications [1]. Natural fibres have received great attention from researchers and industrialists due to their biodegradability, better mechanical properties, easy manufacturing, and overall cost effective quality [2, 3]. Apart from this, the lignocellulosic fibres are lightweight, reduce wear in their production equipment, easily 
available, renewable, non-abrasive, require less energy for processing, reduce furnished product density and absorbed $\mathrm{CO}_{2}$ during growth [4-6]. The lignocellulosic fibres can be mixed, either with thermosetting or thermoplastic polymer matrix, to produce composites $[7,8]$. Composite which use thermosetting polymer shows brittleness and inability to repair. Many of the thermoplastic-based composites offer excellent resistance to impact loading, the possibility of thermoforming and shaping at elevated temperatures and the potential for thermal joining and repair, as well as recycling. Amongst various natural fibres, both coir and jute fibres, are widely available and cheap, in context, to the economic condition of Bangladesh. Coir and jute are lignocellulosic fibres mainly consist of cellulose, lignin, and hemicelluloses. Higher lignin content in coir than jute fibre has made it highly weather resistant [9]. The coir fibre is relatively water-proof and one of the few natural fibres resistant to damage by salt water. They absorb lesser water extent as compared to all other natural fibres, including jute, due to its less cellulose content. Both fibres are biodegradable and recyclable. These are renewable resources and these materials are $\mathrm{CO}_{2}$ neutral. These fibres also possess a much higher strength and stiffness as compared to the matrices [10]. The objective of present research is to develop a hybrid composite by using inexpensive and eco-friendly jute and coir fibres, thus improving a new era of eco-friendly composites. Physical and mechanical properties of the composites were subsequently characterised.

\section{MATERIALS AND METHODS}

\section{Materials}

A commercial grade polyethylene (PE), coir, and jute were used in this study. They were collected from the local market. The PE is white in colour and in granular form with a melting point of $135^{\circ} \mathrm{C}$. Jute fibre is extracted from bundle and coir fibre is collected from coconut. Jute fibre consists of $65.2 \%$ cellulose, $22.2 \%$ hemi-cellulose and $12.5 \%$ lignin. On the other hand coir fibre has $43.4 \%$ cellulose, $0.50 \%$ hemi-cellulose and $45.9 \%$ lignin. The die (Figure 1) used to prepare composite is made of aluminium, which is by machining aluminium plate to a desired shape $(25.4 \mathrm{~cm} \mathrm{x} 18.8 \mathrm{~cm})$ and depth of $0.8 \mathrm{~cm}$.

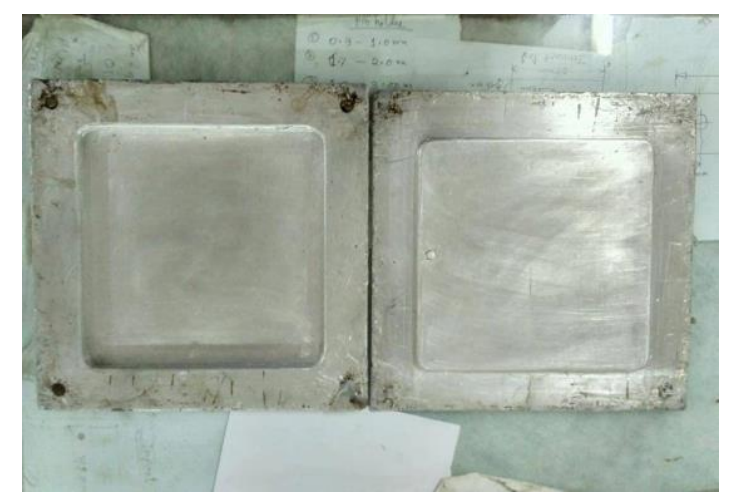

Figure 1. Picture of die used to prepare composites.

\section{Manufacturing of Composites}

Hybrid composite of polyethylene matrix with a varying amount of jute and coir fibres were manufactured by using hot press technique in a $25.4 \times 18.8 \times 0.8 \mathrm{~cm}$ die 
(Figure 1), as mentioned in the previous section. A hydraulic type machine with a maximum load of $35 \mathrm{kN}$ and a maximum temperature of $300^{\circ} \mathrm{C}$ was utilised. The fibre loading was varied at $5 \mathrm{wt} . \%, 10 \mathrm{wt} . \%$ and $15 \mathrm{wt} . \%$, with the jute to coir ratio of 1:1. Fibres were cut to 3-5 mm length. Firstly, the required amount of fibres and PE were weighed in a balance. Then, to remove moisture, fibres and PE were oven dried at $80{ }^{\circ} \mathrm{C}$ for 20 minutes before each composite is prepared. In some cases, they were mixed properly in a container by applying heat from a hot plate. The application of heat (much below the melting point of $\mathrm{PE}$ ) during mixing enables the fibres to adhere with the PE granules since no additional adhesive was used. Mould releasing agent was uniformly sprayed on it for easy removal of composite. The fibre and PE mixture was then placed inside the die. The fibre matrix mixture was allowed to press at $30 \mathrm{kN}$ pressure. The temperature was initially raised to $120^{\circ} \mathrm{C}$ and held for around $12-15$ minutes, after that the temperature was raised to $(150-160)^{\circ} \mathrm{C}$, depending on the required thickness. A water cooling system was used for cooling the system gradually. Then the PE composite specimen was carefully discharged from the mould after allowing it to cool at room temperature. Since the compression temperature was higher than the PE melting point $\left(135^{\circ} \mathrm{C}\right.$ ), the matrix had melted but the fibres (melting point $>220{ }^{\circ} \mathrm{C}$ ) remained intact. Figure 2 shows a composite and its raw materials.
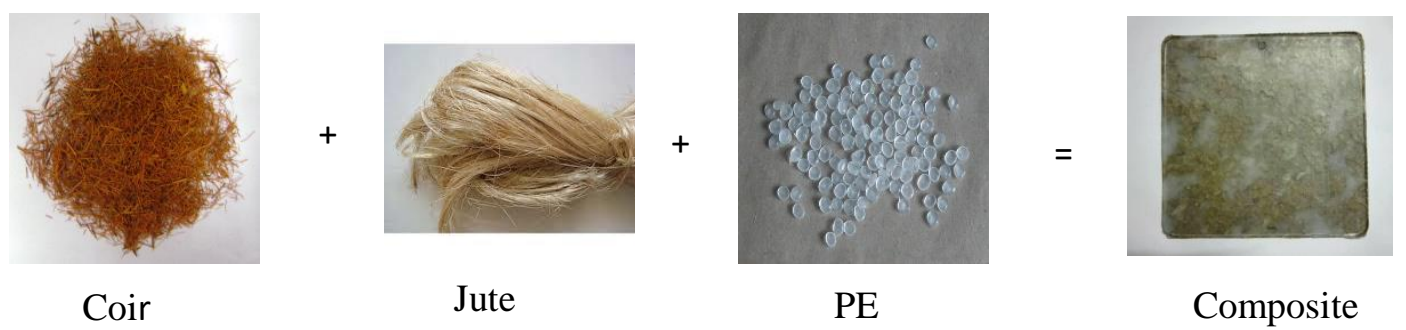

Figure 2. Preparation of composite.

\section{Mechanical Testing}

Tensile, impact, flexural, and hardness tests were carried out in this study. In each case, five samples were tested and the average value was taken. Tensile tests were conducted according to ASTMD 638-01 [11] by using a universal testing machine at a crosshead speed of $4 \mathrm{~mm} / \mathrm{min}$ (Figure 3). Each test was continued until tensile failure was achieved. The dynamic charpy impact test of the composite was conducted by using an impact tester MT 3016 according to ASTM D790-07[12]. Static flexural tests were carried out according to Page 1 of 1,720 results ASTM D570-98 [13] by using a universal testing machine (Figure 3). The hardness of the composite was measured by using a shore hardness testing machine.

\section{Water Absorption Testing}

Water absorption test was also performed by using rectangular specimens of dimension $39 \mathrm{~mm} \times 10 \mathrm{~mm} \times 4.1 \mathrm{~mm}$. The specimens were oven dried at $105^{\circ} \mathrm{C}$, cooled in a desiccator by using silica gel and immediately weighed. A Denver Instron balance was used for weight measurement. The dried and weighed specimens were immersed in hot distilled water according to Page 1 of 281 results ASTM D570-98 [14] for 2 hours. After immersion, the excess water on the surface of the specimens was removed with a soft cloth. The final weight of the specimens was then taken. Then increase in specimen weight s was calculated. 

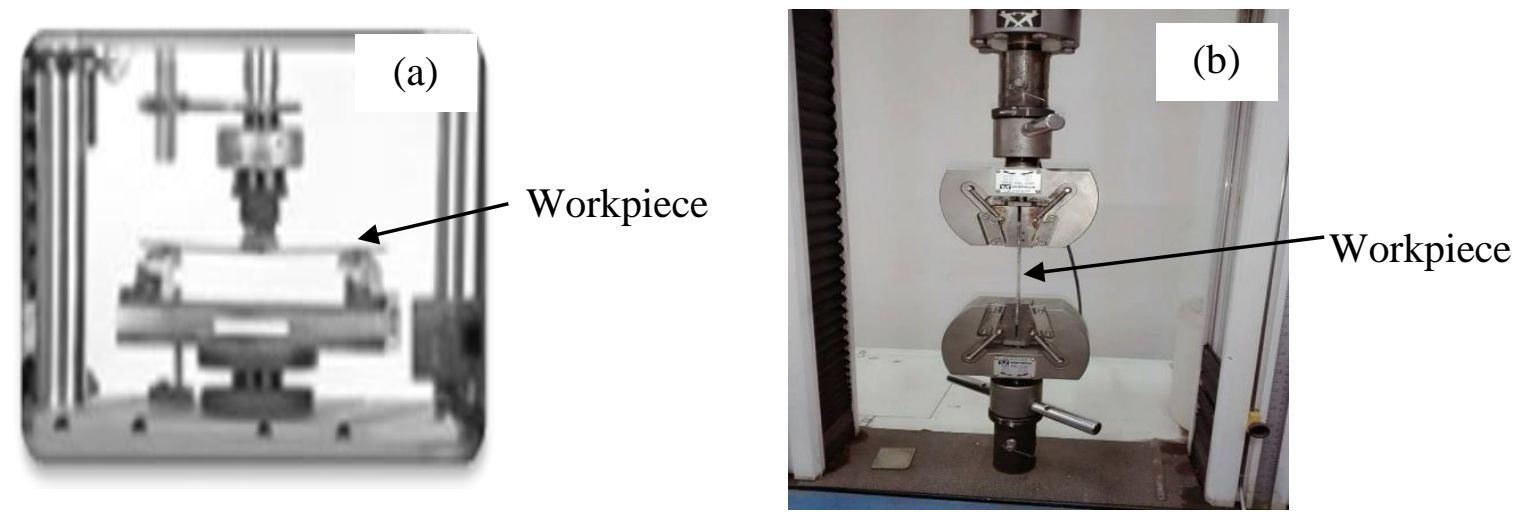

Figure 3. Picture of (a) flexural and (b) tensile tests set up with a workpiece.

\section{Scanning Electron Microscopy}

The interfacial bonding between the fibres and PE matrix in manufactured composites and a Scanning Electron Microscope (Philips XL 30) was used to examine their tensile fracture surfaces. The composite surface was initially made conductive by applying a gold coating with the use of a sputtering machine. The composite was then taken into SEM, a vacuum was created and micrographs were taken.

\section{RESULTS AND DISCUSSION}

\section{Tensile Properties}

Tensile properties of the composite samples were measured for each fibre content $(5 \%, 10 \%$, and $15 \%)$ with the help of stress/strain curves. The tensile strength and Young's modulus of raw coir and jute fibres (Jute: coir $=1: 1$ ) reinforced hybrid polyethylene composites at different fibre loadings are summarised in Figure 4. The tensile strength decreased with an increase in fibre loading. As the fibre loading was increased the interfacial area between the fibre and matrix also increased, which was weaken because of interfacial bonding worsening between cellulose based hydrophilic filler (jute and coir) and hydrophobic PE matrix [9]. This consequently decreased the tensile strength [5]. The same trend was also observed by other researchers in their work [15-18].

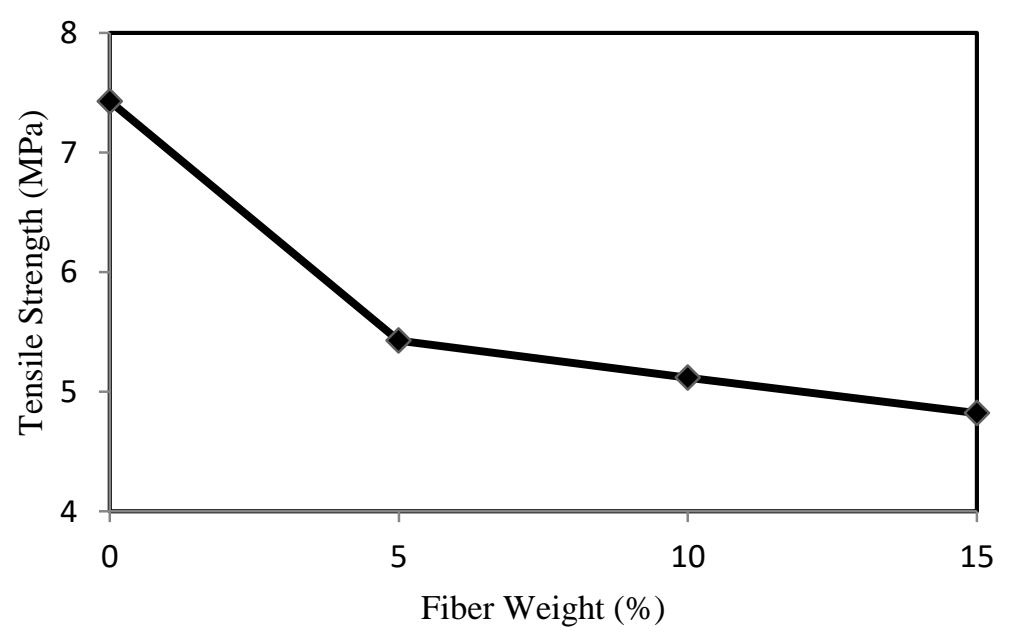

Figure 4. Variation of tensile strength against fibre loading. 
The Young's modulus values of coir and jute fibres reinforced polyethylene composites for different fibre loadings are shown in Figure 5. It is observed that Young's modulus increased with an increase in fibre loading. This is because with an increase in fibre content, the brittleness of the composite increased and stress/strain curves became steeper [9]. Poor interfacial bonding creates partially separated micro spaces, which obstructed stress propagation between the fibre and matrix. As the fibre load increased, the degree of obstruction also increased, which in turn increased the stiffness [18]. Other researchers also discovered the same trend in their research $[4,5,15,19]$.

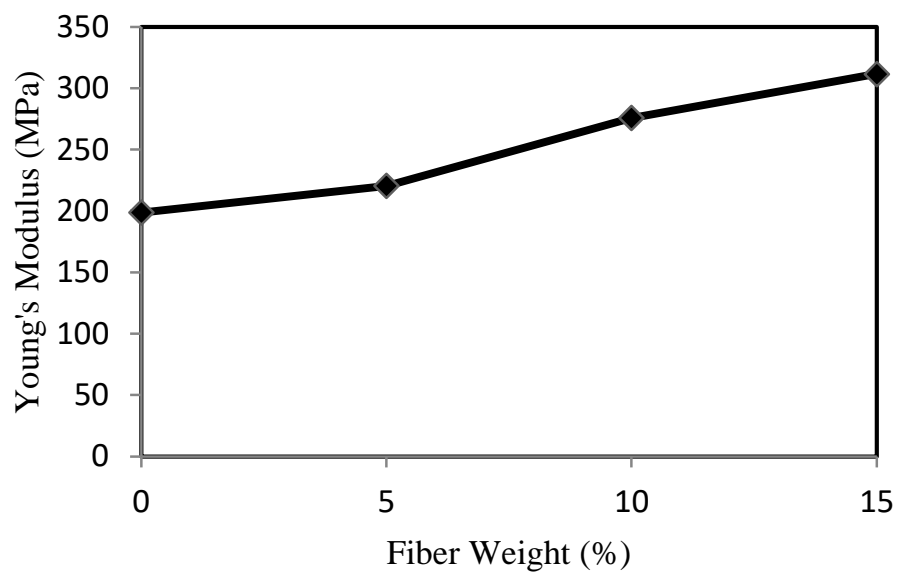

Figure 5. Variation of Young's modulus against fibre loading.

The elongation $\%$ at break of the composites against fibre loading is shown in Figure 6. The figure reveals that elongation at break was considerably reduced with enhancement of fibre fraction. Both coir and jute fibre was stiffer than the polyethylene matrix, thus they had lower elongation \% at breaking than the PE matrix. As a result, elongation at break decreased with increase in fibre content of PE composites.

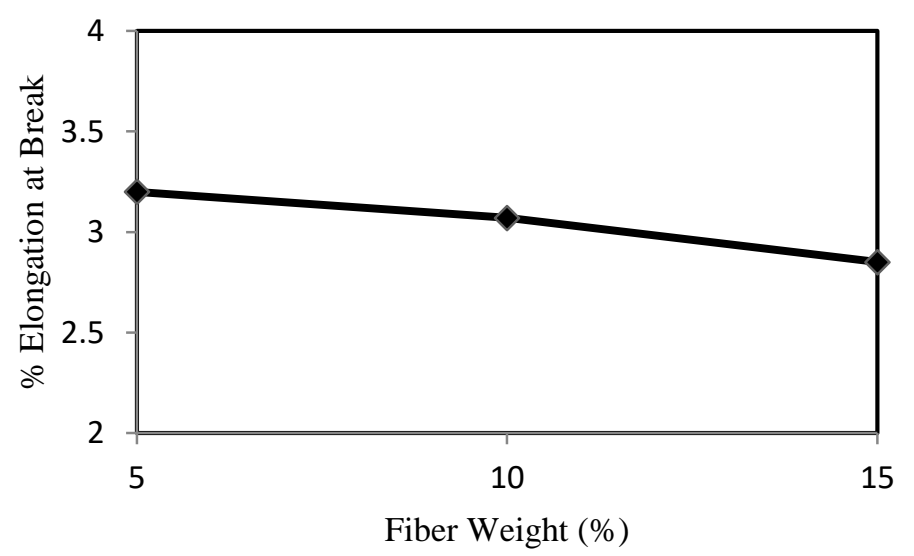

Figure 6. Variation of percentage elongation at break against fibre loading.

\section{Flexural Properties}

Flexural properties (flexural strength and flexural modulus) were measured for samples of each fibre content with the help of flexural stress/strain curves and respective equations. The flexural strength of raw coir and jute fibre reinforced hybrid polyethylene composites at different fibre loading are shown in Figure 7 . The flexural strength 
increased with an increase in fibre loading, which is in agreement with the findings by other researchers. This may be due to the favourable polymer chain entanglement with the filler, which has overcome the weak filler-matrix adhesion with increased filler content [17]. The same trend was observed in previous research $[4,16,20]$.

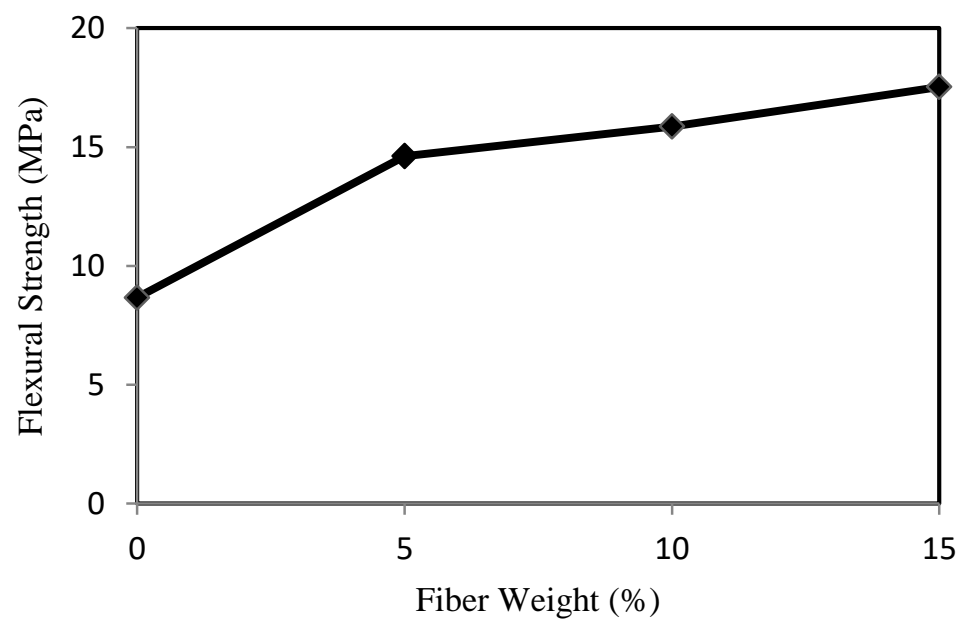

Figure 7. Variation of flexural strength against fibre loading.

The flexural modulus values of raw coir and jute fibre reinforced hybrid polyethylene composites at different fibre loading was shown in Figure 8. The flexural modulus increased with an increase in fibre loading. Since both coir and jute are high modulus material, higher fibre concentration demands higher stress for the same deformation. Thus the incorporation of the filler (rigid coir and jute) into the soft polyethylene matrix resulted in increased modulus [17]. Other researchers also discovered the same trend in their work $[16,19,20]$.

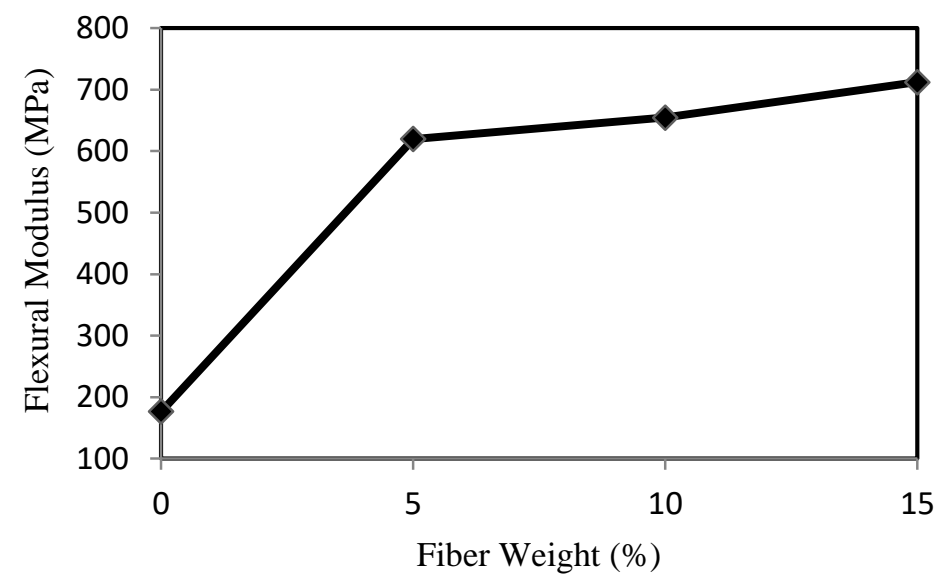

Figure 8. Variation of flexural modulus against fibre loading.

\section{Impact Strength}

Variation of the Charpy impact strength with different fibre loading for raw coir and jute fibre reinforced hybrid composite is shown in Figure 9. The impact strength increased with fibre loading. Impact strength of a material provides information regarding the 
energy required to break a specimen of a given dimension, the magnitude of which reflects the materials ability to resist a sudden impact. The impact strength of the fibre reinforced polymeric composites depends on the nature of the fibre, polymer, and fibrematrix interfacial bonding [21]. As presented in the figure, the impact strength of all composites increased with fibre loading. This result suggests that the fibre is capable of absorbing energy due to favourable entanglement of fibre and matrix [9]. Fibre pull out is found to be an important energy dissipation mechanism in fibre reinforced composites [18]. One of the factors of impact failure of a composite is fibre pull out. With the increase in fibre loading, stronger force is required to pull out the fibres. This, in turn, increased the impact strength [18]. The same trend was observed in previous research $[10,15,18]$.

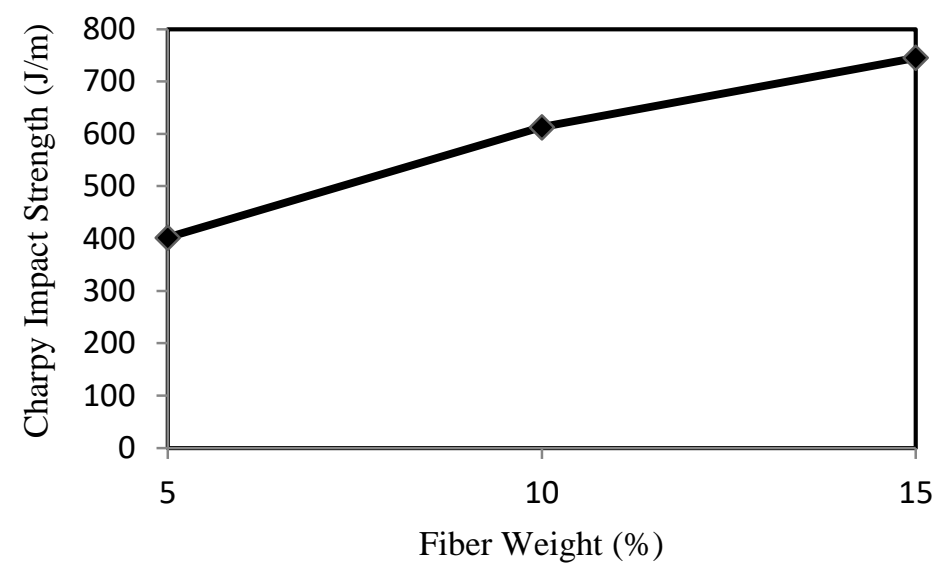

Figure 9. Variation of impact strength against fibre loading

\section{Hardness}

Hardness of a composite depends on the distribution of filler into the matrix. Usually, the presence of a more flexible matrix causes the resultant composites to exhibit a lower hardness. As shown in Figure 10, incorporation of fibre into the PE matrix has reduced the flexibility of the matrix and results in more rigid composites. Due to the increase in stiffness of respective composite, the hardness of jute-coir hybrid PE composites showed a slight increase in trend with an increase in the fibre content. Better dispersion of a filler into the matrix with minimisation of voids between the matrix and the filler also enhanced hardness [22].

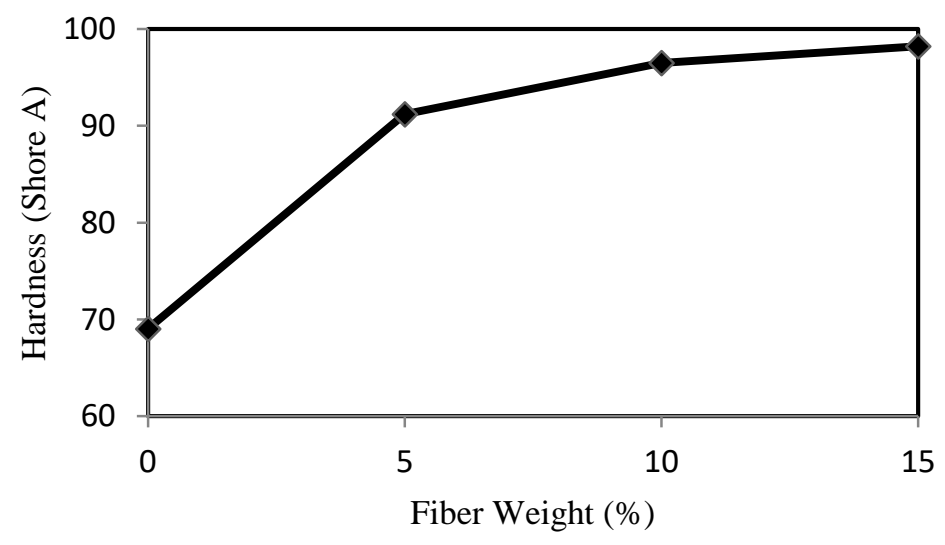

Figure 10. Variation of hardness against fibre loading. 


\section{Water Absorption Characteristics}

Natural fibre has the tendency to absorb water due to the presence of hydrophilic hydroxyl groups of cellulose, hemicelluloses, and lignin. The water absorption characteristics is shown in Figure 11. With an increase in fibre loading, the amount of hydrophilic hydroxyl groups of cellulose, hemicelluloses, and lignin content of overall composites also increased. As a result, the water absorption of coir and jute fibre reinforced polyethylene composites increased with an increase in fibre content inside PE [18].

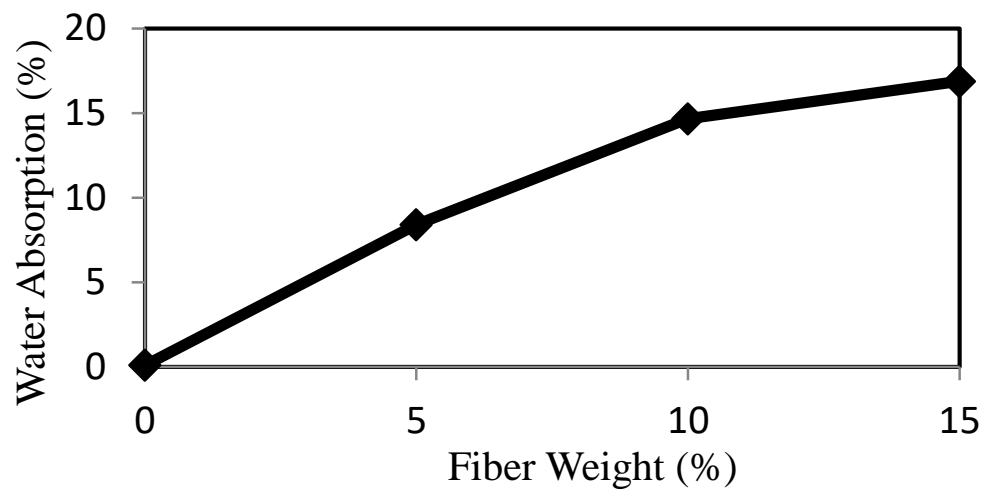

Figure 11. Variation of water absorption against fibre loading.
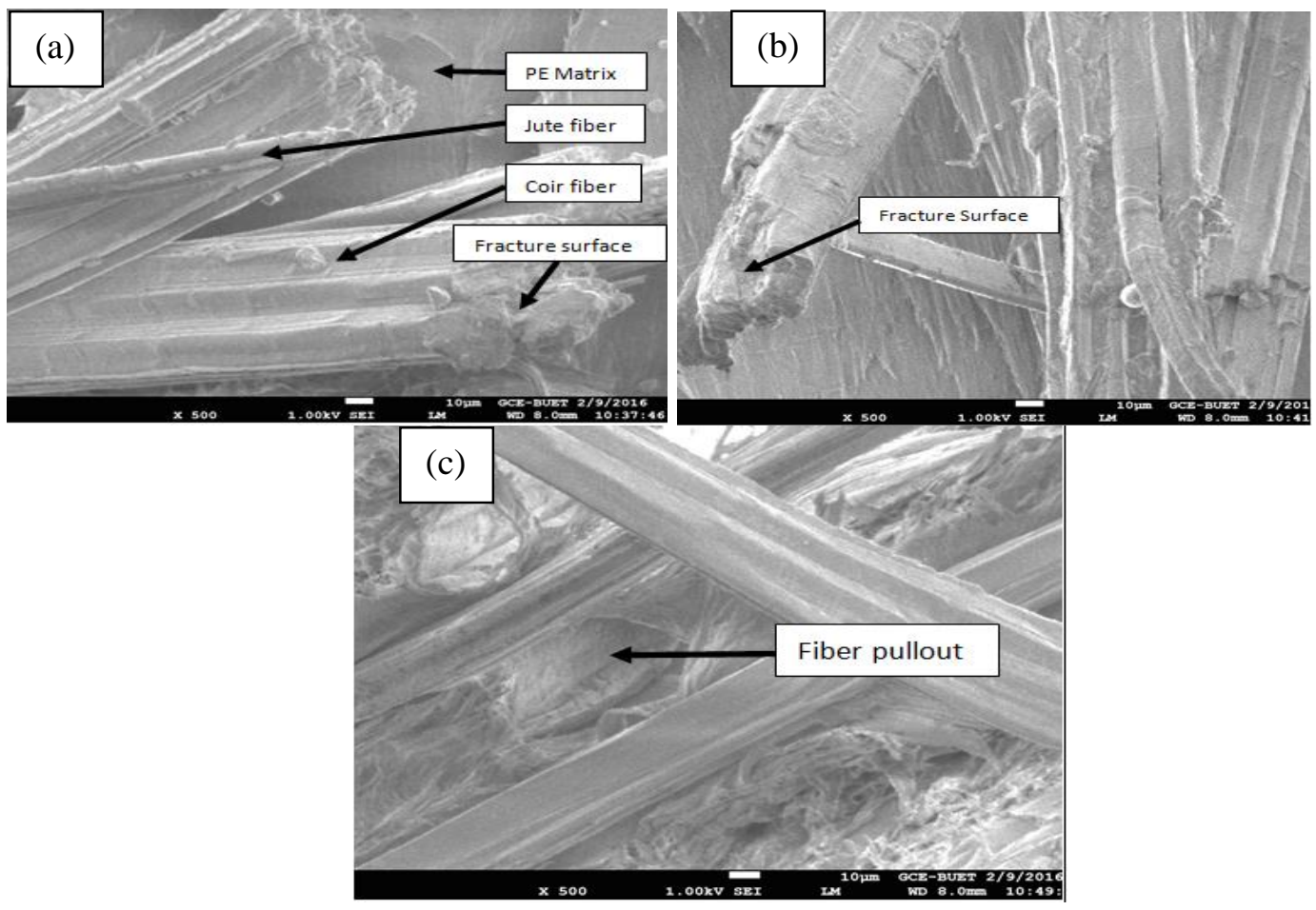

Figure 12. SEM micrographs of tensile fracture surface of (a) $5 \%$, (b) $10 \%$ and (c) $15 \%$ fibre reinforced PE composite.

\section{Surface Morphology}

Tensile fracture surface of $5 \mathrm{wt} . \%, 10 \mathrm{wt} . \%$, and $15 \mathrm{wt} . \%$ coir-jute fibre reinforced hybrid polyethylene composites are shown in Figure 12. The figure shows the presence of both 
coir (comparatively larger in diameter) and jute (comparatively smaller in diameter) fibre in polyethylene composite. The main reason for poor mechanical properties of raw fibre reinforced composites is weak bonding between the fibre and matrix [23]. This is evident in the micrographs obtained from a scanning electron microscope. According to the scanning electron micrographs, $15 \%$ fibre reinforced composites (Figure 12) showed a favourable entanglement between the fibre and the matrix amongst all manufactured composites. As a result, $15 \%$ fibre reinforced composites yields the best set of mechanical properties as compared to other fibre loaded composites [23].

\section{CONCLUSIONS}

In this study, jute and coir fibre reinforced hybrid polyethylene composite was manufactured by hot press technique. The level of fibre loading was varied at $5 \mathrm{wt} . \%$, $10 \mathrm{wt} . \%$, and $15 \mathrm{wt} . \%$. The tensile strength of the composite decreased with an increase in fibre loading. Whereas, Young's modulus was increased with fibre loading. Flexural strength, flexural modulus, Charpy impact strength, and hardness values are all increased with the increase in fibre loading. Water absorption increased with an increase in fibre loading. Scanning electron microscopic analysis showed the strongest adhesion between fibre and matrix when $15 \%$ fibre was reinforced into polyethylene matrix. As a result, the $15 \%$ fibre composite yielded the best set of mechanical properties as compared to other composites. Further modification can be done by treating the fibre and improving fibre matrix inter-bonding.

\section{ACKNOWLEDGMENT}

The authors are grateful to Bangladesh University of Engineering and Technology (BUET) for technical and financial support during the work.

\section{REFERENCES}

[1] Sultana Mir S, Hasan M, Hasan S, Hossain M, Nafsin N. Effect of chemical treatment on the properties of coir fiber reinforced polypropylene and polyethylene composites. Polymer Composites. 2015.

[2] Kasim AN, Selamat MZ, Daud MAM, Yaakob MY, Putra A, Sivakumar D. Mechanical properties of polypropylene composites reinforced with alkaline treated pineapple leaf fibre from Josapine cultivar. International Journal of Automotive and Mechanical Engineering. 2016;13:3157-67.

[3] Fairuz AM, Sapuan SM, Zainudin ES, Jaafar CNA. Effect of filler loading on mechanical properties of pultruded kenaf fibre reinforced vinyl ester composites. Journal of Mechanical Engineering and Sciences. 2016;10:1931-42.

[4] Joseph S, Sreekala M, Oommen Z, Koshy P, Thomas S. A comparison of the mechanical properties of phenol formaldehyde composites reinforced with banana fibres and glass fibres. Composites Science and Technology. 2002;62:1857-68.

[5] Lou C-W, Lin C-W, Lei C-H, Su K-H, Hsu C-H, Liu Z-H, et al. PET/PP blend with bamboo charcoal to produce functional composites. Journal of Materials Processing Technology. 2007;192:428-33.

[6] Thwe MM, Liao K. Effects of environmental aging on the mechanical properties of bamboo-glass fiber reinforced polymer matrix hybrid composites. Composites Part A: Applied Science and Manufacturing. 2002;33:43-52. 
[7] Lee CH, Sapuan SM, Lee JH, Hassan MR. Mechanical properties of kenaf fibre reinforced floreon biocomposites with magnesium hydroxide filler. Journal of Mechanical Engineering and Sciences. 2016;10:2234-48.

[8] Tezara C, Siregar JP, Lim HY, Fauzi FA, Yazdi MH, Moey LK, et al. Factors that affect the mechanical properties of kenaf fiber reinforced polymer: A review. Journal of Mechanical Engineering and Sciences. 2016;10:2159-75.

[9] Siddika S, Mansura F, Hasan M, Hassan A. Effect of reinforcement and chemical treatment of fiber on The Properties of jute-coir fiber reinforced hybrid polypropylene composites. Fibers and Polymers. 2014;15:1023-8.

[10] Karmarkar A, Chauhan S, Modak JM, Chanda M. Mechanical properties of wood-fiber reinforced polypropylene composites: Effect of a novel compatibilizer with isocyanate functional group. Composites Part A: Applied Science and Manufacturing. 2007;38:227-33.

[11] Norma A. Standard Test Method for Tensile Properties of Plastics. Annu B ASTM Stand. 2004:1-15.

[12] ASTM I. Standard test methods for flexural properties of unreinforced and reinforced plastics and electrical insulating materials. ASTM D790-07. 2007.

[13] American Society for Testing Materials. Standard Test Method for Water Absorption of Plastics. ASTM; 2005.

[14] Testing ASf, Materials. Standard Test Method for Water Absorption of Plastics. ASTM; 2005.

[15] Jamil MS, Ahmad I, Abdullah I. Effects of rice husk filler on the mechanical and thermal properties of liquid natural rubber compatibilized high-density polyethylene/natural rubber blends. Journal of Polymer Research. 2006;13:31521.

[16] Rahman MR, Huque MM, Islam MN, Hasan M. Improvement of physicomechanical properties of jute fiber reinforced polypropylene composites by posttreatment. Composites Part A: Applied Science and Manufacturing. 2008;39:1739-47.

[17] Rahman MR, Huque MM, Islam MN, Hasan M. Mechanical properties of polypropylene composites reinforced with chemically treated abaca. Composites Part A: Applied Science and Manufacturing. 2009;40:511-7.

[18] Yang H-S, Kim H-J, Park H-J, Lee B-J, Hwang T-S. Water absorption behavior and mechanical properties of lignocellulosic filler-polyolefin bio-composites. Composite structures. 2006;72:429-37.

[19] Yang H-S, Kim H-J, Son J, Park H-J, Lee B-J, Hwang T-S. Rice-husk flour filled polypropylene composites; mechanical and morphological study. Composite structures. 2004;63:305-12.

[20] Rana A, Mandal A, Bandyopadhyay S. Short jute fiber reinforced polypropylene composites: effect of compatibiliser, impact modifier and fiber loading. Composites Science and Technology. 2003;63:801-6.

[21] Jayaraman K. Manufacturing sisal-polypropylene composites with minimum fibre degradation. Composites Science and Technology. 2003;63:367-74.

[22] Mishra S, Naik J, Patil Y. The compatibilising effect of maleic anhydride on swelling and mechanical properties of plant-fiber-reinforced novolac composites. Composites Science and Technology. 2000;60:1729-35.

[23] Haque MM, Hasan M. Mechanical properties of betel nut and glass fibre reinforced hybrid polyethylene composites. International Journal of Automotive \& Mechanical Engineering. 2016;13. 